\title{
Administração de presídios públicos e privados diferenças relevantes para sociedade
}

O trabalho em questão vem explanar, para os leitores, informações interessantes, obtidas por pesquisa realizada com o auxílio de documentos, sites e outras fontes confiáveis, sobre um assunto que muito se comenta no país, segurança pública, tendo como foco: a administração de presídios públicos e privados. Assim com os dados obtidos, procura relatar quais diferenças, como se trabalha em questão da ressocialização do preso e seu ambiente carcerário, além de explanar sobre a questão: tem o mínimo de dignidade possível?. Sendo posto isso em relação aos dois sistemas de administração de presídios. Perguntas que a pesquisa busca responder e passar para o público, além de explorar a opinião do autor em relação a qual sistema seria melhor para a sociedade, ajudando assim a segurança do país a melhorar nesse quesito, pois são dados que vem em baixa há anos no Brasil.

Palavras-chave: Administração; Presídios; Presídios públicos; Presídios privados.

\section{Administration of public prisons and private differences relevant to society}

The work in question explains to readers interesting information obtained by research carried out with the help of documents, websites and other reliable sources, on a subject that is widely discussed in the country, public security, focusing on: the administration of public and private prisons. Thus, with the data obtained, it tries to report what differences, how one works in question of the resocialization of the prisoner and its prison environment, besides explaining on the question: has the minimum of dignity possible?. This being so in relation to the two systems of administration of prisons. Questions that the research seeks to answer and pass to the public, in addition to exploring the author's opinion as to which system would be better for society, thus helping the country's security to improve in this area, since data are coming down for years in Brazil.

Keywords: Administration; Prisons; Public prisons; Private prisons.

Topic: Gestão Pública

Reviewed anonymously in the process of blind peer.

Vanderlei José Silva

Centro Universitário Dr. Leão Sampaio, Brasil.

http://lattes.cnpq.br/6533875591449904

vanderleijs61@gmail.com

Tharsis Cidália de Sá Barreto Diaz Alencar (ito

Centro Universitário Dr. Leão Sampaio, Brasil

http://lattes.cnpq.br/5214712222311784

http://orcid.org/0000-0003-4242-9318

tharsis@leaosampaio.edu.br

d

DOI: 10.6008/CBPC2674-6417.2019.001.0001
Received: $12 / 01 / 2019$

Approved: 20/04/2019
Referencing this:

SILVA, J. S.; ALENCAR, T. C. S. B. D.. Administração de presídios públicos e presídios privados diferenças relevantes para sociedade. Management Journal, v.1, n.1, p.1-11, 2019. DOI:

http://doi.org/10.6008/CBPC2674-6417.2019.001.0001 


\section{INTRODUÇÃO}

O início de 2019 foi bastante caótico no sistema de segurança brasileira, que, infelizmente, é um assunto bastante discutido negativamente, em 2017 esse assunto tornou-se repercussão mundial também, pois, muitos confrontos entre faç̧ões, tanto fora quanto dentro dos presídios, foram observados, rebeliões que causaram mortes em oito estados do pais, a população estava abismada, não só com a violência usada pelos integrantes, mas também com a sequência dos ataques em dez presídios distribuídos em distintas regiões do brasil. Com confusões em presídios, de uma longitude considerável, como o de Santa Catarina e Amazonas, mostra que o Brasil perdeu plenamente o domínio da situação. Reforçando ainda mais essa ideia, vemos a liberdade que detentos tem para se locomover nas dependências das penitenciarias brasileiras. Diante desse domínio que o crime detém nas penitenciarias, demostra que esses problemas são ligados diretamente a gestão, pessoas experientes e de boa observação identificaram problemas e possíveis soluções, desses problemas, mostrando que o administrador tem papel importantíssimo nesse assunto (MIRANDA, 2017).

Com a crise no sistema de segurança e superlotação dos presídios, houve a curiosidade de pesquisar a administração dos presídios brasileiros, tendo como foco da pesquisa à administração pública e privada dos próprios, buscando informar ao público leitor quais as diferenças, como porta-se a organização, qual trabalha melhor com a ressocialização do preso à sociedade e o ambiente carcerário, qual proporciona ao indivíduo um ambiente mais humano que passe para ele o mínimo de sobrevivência possível. A pesquisa tem como característica básica a abordagem qualitativa, caráter exploratório, descritiva e documental, buscando informações que passem para o leitor a importância de saber sobre esse assunto que muito se repercute mundialmente, trazendo um olhar negativo do mundo para o país.

\section{REVISÃO TEÓRICA}

\section{Administração}

Caravantes et al. (2008) relata, que em meados do século XIX e início do século XX, com a chegada da revolução industrial, as empresas entraram em crises, pois tudo estava mudando e era necessário uma organização na forma de trabalho das mesmas, tendo como principal nome dessa organização, o de Frederick Winston Taylor (1995), o pai da administração e outros nomes também, como Gantt e Gilbreth, tiveram uma grande significância nesse contexto de organização.

Administrar é um processo que ocorre diariamente na vida de todos, a necessidade de administrar

vem do enfrentamento de variáveis que integram uma estrutura formal como humanas, tecnologia, restrições ambientais, entre outras mais, não sendo apenas ligada a esfera de produção de bens e serviços de empresas, até mesmo em um âmbito familiar é preciso ter um grau de administração, quanto maior a dificuldade de implementar atividades em um determinado grupo, maior é a imposição de pessoais que tenham estudos na ciência da administração. Qual quer pessoa em qual quer momento, ela só ou em grupo, pode iniciar um negócio, onde esse negócio precisara ser gerenciado por alguém, este que seja responsável 
para identificar prováveis problemas, minimizá-los ou até mesmo prevê-los, isso em função de um bem maior para organização. Visto como um processo de integração que busca resultados específicos, portanto o administrador cria, dirigi e mantem total controle da organização (KAWSNICKA, 2009).

Complementando o que Kawsnicka relatou, Lacombe et al. (2016) dizem que o administrador tem como principal ponto a obtenção de resultados através de uma equipe onde ele é responsável para coordenar e supervisionar esse grupo, o seja, o administrador depende de outras pessoas para obter resultados, porém, ele o qual lidera e toma decisões em nome dos membros da sua equipe. Nessa nova era da informação ter o domínio de armas para persuadir e fazer com que terceiros trabalhem para você na busca de resultados positivos para organização é crucial, pois o conhecimento está na mente de muitos mas apenas as pessoas que tenham habilidade podem transforma conhecimento em resultados, isso mostra que ter o conhecimento administrativo não necessariamente quer dizer que você como administrador venha ater resultados na organização. Mesmo que não trabalhe em uma empresa o administrador sempre tem que estar atento as oportunidades sempre agindo como empresário, transformando recursos em produtos, seja ele um bem ou serviço, sempre buscando agradar seu público.

O autor Certo (2013) comenta que a administração é essencial para a sociedade no geral e também para àquelas pessoas que são gerentes, o mesmo fala, que segundo estatísticas americanas, o aumento de cargos na área administrava aumentou desde 1950, onde saiu de $10 \%$ para $18 \%$ do total de empregos naquele país, tornando-se uma área bem abrangente no mercado, pois, muitas pessoas que estudaram para outros areais, tais elas como professores, contadores, escritores etc., tiraram a administração como sua fonte de renda, dada o quanto ela se tornou importante nos dias de hoje. Diante desses fatos relatados sobre administração, o intuito maior da pesquisa é falar de administração dos presídios públicos e presídios privados, entretanto, antes de falar sobre a administração, começaremos falando de presídios que é um dos pontos que a pesquisa abrange.

\section{Presídios}

Pinto (2009) relata que no ano de 2010 o Brasil tinha uma carência 200.000 vagas para detentos, causando assim uma situação precária dos presídios, locais sub-humanos para se conviver, sujos, lotados e com presos de várias condenações diferentes de periculosidades alta. Vale lembrar que o país por conta dessa situação não vem obedecendo tratados internacionais de direitos humanos, exemplos: o Pacto Internacional dos Direitos Civis e Políticos (1996), onde no seu art. 10 informa que toda pessoa detida de sua liberdade tem por direito ser tratada com humanidade, com o mínimo de respeito dignidade específico a pessoa humana; bem como também, o pacto de São José da Costa Rica relatando, no seu art. 5, que pessoas que estão no meio do processo devem ficar separadas dos já condenados, devendo ser submetidos a tratamentos de pessoas não condenadas.

Essas características dos presídios foram dadas a muito tempo atrás, vem desde antes da ditadura. O sistema penitenciário tinha um grande envolvimento com a segurança nacional, tendo como seguimento a retenção de políticos que seriam da oposição e/ou qualquer autor de criminalidade, vindo como 
consequência a prisão dos indivíduos suspeitos e também perseguidos, mas, diante dessa forma de agir da segurança pública, ocasionou a lotação dos presídios, maus tratos e abuso de poder contra os presidiários. Uma triste verdade que acompanham os presídios no Brasil, isso mostra o descaso que vem acompanhando o sistema carcerário há muitos e muitos anos, causando vários estragos para a segurança pública do país (SALLA, 2006).

Com a implantação do Departamento Penitenciário Nacional - DEPEN, secretários assumiram o cargo, um dos que assumiu, entre os anos de 1999 e 2006, foi o Nagashi Furukawa, o qual em entrevista ao CEBRAP comentou as dificuldades enfrentou no sistema penitenciário, o mesmo comenta que as maiores dificuldades enfrentadas no departamento era a questão de espaço, ao chegar na secretaria de segurança pública de São Paulo havia mais ou menos 90 prisões, com espaço para 30 presos, porém eram ocupadas por 200, sem contar com o Carandiru, que recebia cerca de 800 presos por mês com uma ocupação para 3.300, mas no presídio continha 7.000 presidiários, ou seja, não tinha como manter um sistema organizado se não tinha espaço adequado para os presos. Nunca foi obtido isso, por mais que se trabalhasse, mas em sua gestão na secretaria, foram inauguradas cerca de 82 novas unidades prisionais, em média, uma por mês, com isso foram mais 60.000 vagas abertas e mesmo assim não foi o bastante para enfrentar a quantidade de presos que tinha no estado de São Paulo (SALLA, 2008).

Outra dificuldade enfrentada foi a cultura dos diretores e funcionários mais antigos, eles tinham uma dificuldade enorme para mudanças, com uma forma de administrar antiga que veio de 40 a 50 anos atrás, ainda era a forma que eles usavam para administrar o sistema penitenciário. entrosar a secretaria de segurança pública também foi uma dificuldade, pois em sua mente seria correto ter apenas uma pessoa para comanda o sistema, exemplo um subsecretário de segurança público ou um subsecretario de administração penitenciário, podem relatar que seria trabalho para o governado sim, porém ele não tem tempo nem domínio para coisas que acontecem diariamente, isso mostra o quanto é difícil administra uma secretaria de segurança o quanto tem que melhorar para passar o mínimo de satisfação para os detentos por mais que eles sejam exclusos da sociedade naquele momento de cárcere (SALLA, 2008).

\section{Administração de presídios}

Sá (2003) diz que são dois os tipos de administração de presídios: à administração de presídio pública à administração privada. Mas, cada uma trabalha de formas bem distintas, enquanto uma tem toda a sua organização de trabalho, espaço, higiene, tudo adequado a seus devidos fins, a outra é justamente o contrário tendo aí uma diferença de comportamento entre os presidiários em virtude da sua reabilitação no meio da sociedade. Usando de uma forma antiga de administrar as prisões, os agentes tinham como comum, normal, sempre o autoritarismo empregando muita violência para com os detentos, porém, com o tempo, novas gerações começaram a mudar esse perfil de agentes e administradores de presídios.

O próprio Sá complementa dizendo que a democratização do país na década de 80 quando o regime penitenciário estava em um período bastante confuso, pois de um lado tinha os que ainda usavam a forma antiga de regime, onde as forças militares detinham o poder, do outro lado uma geração que vinham com 
uma nova visão, de humanização, eles agora estavam olhando o ser humano além do infrator e estavam buscando leis que o protegesse de certos abusos de poder do agente. Teve como um modelo inaugural essas práticas os governos de Leonel Brizola e Franco Montoro, nesses governos foi crescendo timidamente, porém com uma eficácia enorme os avanços quanto os direitos dos detentos. Buscou uma maior transparência do poder público quando se falava da administração dos presídios, isso para inibir as práticas usadas antes contra os detentos, com isso foram criadas secretarias de administração penitenciárias separada das secretarias de segurança pública, nas décadas seguintes havendo ouvidorias e abertura de novas vagas, tudo em busca de amenizar a população carcerária (SÁ, 2003).

Adorno et al. (2007) complementa dizendo que esses descasos de administração são muito antigos, vem desde antes da ditadura, porém, é fato que com a ditadura houve um aumento enorme de prisões e os espaços não era adequado para a quantidade de pessoas que lá continha, tornando-se um local desumano para os detentos, tendo também outros locais que eram usados para torturas e muita humilhação, anos se passaram e essas práticas continuavam, era visto o quanto as autoridades públicas usavam do poder militar para coagir os detentos, uma forma de administração bastante abusiva, constrangedora e humilhante, descaso total com os detentos. Porém, uma nova visão entre os administradores surgiu, a preocupação em buscar mudar esse retrospecto negativo, o qual ficou sobre os presídios do nosso país.

\section{Administração de Presídios Públicos}

Infelizmente como uma grande parte dos serviços públicos no país, a administração pública de presídios tem muito a desejar, problemas que perduram a muito tempo. Uma análise feita por uma CPI (Comissão Parlamentar de Inquérito), no ano de 1976, tinha o intuito de examinar o sistema penitenciário do país, assim foi costado um ambiente sem condições básicas de convívio, local altamente insalubre, abusos sexuais e morais contra adolescentes, adultos, homens e mulheres que, com uma frequência muito grande, se encontravam na mesma cela. O que impressiona é os resultados encontrados naquele ano, os quais prolongam-se até os dias atuais, com uma diferença, a população carcerária, naquela época, era bem menor comparando com os dias de hoje, porém os problemas continuam: ociosidade, superlotação, violência, falta de atendimento as necessidades básicas dos presidiários, etc. (OSTERMANN, 2010).

Corroborando com Ostermann (2010), Sá (2003) argumenta que a administração pública usa de um ambiente hostil, tratando seus detentos como objetos, onde terão que aprender, de forma arbitrária e autoritária, modos para voltar ao meio da sociedade e não praticarem mais delitos, com isso foi entendido por Sá, que a forma de administrar influi diretamente no comportamento do indivíduo, quando recolocado no meio da sociedade.

Concordando com os autores anteriores Hauser (1997) fala que os presídios brasileiros têm como princípio a superlotação, falta de higiene, maus tratos, educação e trabalho péssimos, alimentação irregular sem contar na falta de assistência médica e jurídica, isso quando elas existem. Em 2010 foi estimado que cerca de 9.000 presos viviam nessa situação, mesmo com suas penas já cumpridas, tudo isso por conta da 
falta da assistência jurídica, isso mostra o quanto é difícil ter um sistema capaz de recriar a cultura de ressocialização do indivíduo, com prisões com nenhuma boa estrutura de repassar isso para os presos.

\section{Administração de Presídios Privados}

O termo privatização tem como significado a administração por terceiros, o seja o estado abre mão de administrar o presídio, dando abertura para empresas assumirem esse papel, é um termo muito amplo onde uni ideias ou linhas práticas para a confirmação e realização de seus objetivos (CHIES, 2000).

Ostermann (2010) relata que existem dois modelos de privatização de presídio, o modelo do EUA (Estados Unidos da América) e o Francês ou Europeu. Com o modelo americano o estado abre mão completamente da administração do presídio, ficando como responsável somente com a fiscalização das leis e termos contido no contrato com a empresa responsável, diferente do modo Francês que atua juntamente com o estado, formando uma administração mista, o estado continua com a direção do presídio, porém, terceiriza alguns serviços como por exemplo: construção das unidades prisionais, alimentação, esporte, assistência social, entre outros, o seja, o estado tem como responsabilidade apenas a direção, as outras funções seria de empresas contratadas, que para alguns autores tem uma forma diferente de agir.

Sá (2003) considera que administração terceirizada veio com um pensamento diferenciado, visando a humanização, o bem estar dos presos buscando desde o início recolocar o indivíduo de volta a sociedade, proporcionando a ele um ambiente flexível e favorável ao objetivo proposto. Para ele, a diferença entre os dois ambientes tem uma importância essencial no comportamento dos presidiários, na administração privada tem um ambiente que se mostra agradável, organizado fazendo com que o detento pense melhor e não volte a praticar novos delitos, pois o espaço onde ele se encontrava proporcionava a ele, de certo modo, está entre a sociedade, por mais que ele estivesse em cárcere privado, tornando mais fácil para o indivíduo voltar ao âmbito social.

\section{METODOLOGIA}

Tendo em vista que a pesquisa busca comparar a administração de presídios públicos e presídios privados, a característica da pesquisa é dada como básica, pois se trata de uma pesquisa que gerará novos conhecimentos aos leitores. A pesquisa básica é uma busca de conhecimento simples por hipóteses ou respostas de questões impostas no início da pesquisa, são diretamente ligadas ao desenvolvimento científico. Gerhardt et al. (2009) complementam dizendo que a pesquisa básica tem como maior objetivo gerar conhecimentos novos, onde ajudaram no avanço da ciência e interesses universais.

O presente trabalho tem como característica de abordagem a qualitativa, pois a pesquisa busca passar para o leitos dados documentais e não números, onde Goldenberg (2006) diz que a pesquisa qualitativa não se prende a representações numéricas, ela está preocupada, sim, com o entendimento do indivíduo no âmbito social. Tendo em vista que os pesquisadores que usam esse tipo de abordagem são contra a ideia que exista apenas um tipo de pesquisa para as ciências existentes, isso por usarem uma metodologia própria, evitando em suas pesquisas colocarem seus julgamentos e preconceitos, deixando 
claro para os leitores o objetivo da pesquisa. A pesquisa qualitativa tem questões bem particulares, tendo preocupações com a ciência social, com um nível de realidade que não pode ser quantificado. Desta forma a pesquisa trabalha como motivos, crenças, valores, atitudes e significados, o que condiz com relações de espaços mais profundos daquilo que não pode ser reduzido a variáveis, os fenômenos operacionais.

A pesquisa é exploratória por ter uma familiaridade maior com o problema, isso ajuda a buscar hipóteses e torná-lo mais explícito à sociedade, tendo um planejamento flexível, pois, com esse tipo de pesquisa, as ideias são aprimoradas ou intuições são descobertas de modo que, os mais variados aspectos sobre o fato estudado, seja exporto para os leitores. A pesquisa tem como caraterística o levantamento bibliográfico, buscando informações em fontes seguras e de respaldo no meio educacional (GIL, 1999). Gerhardt et al. (2009) concordam quando dizem que o pesquisador busca mais informações para saber o máximo sobre o assunto, através de abordagens com referenciais claras e de fácil entendimento para os leitores, explorando todo material possível que venham a adquirir.

Trata-se de uma pesquisa descritiva, pois Vergara (2005) afirma que por se tratar de uma pesquisa que tem característica de atender formas mais adequadas, o qual pretendem expor fenômenos e suas características. Vieira (2002) admite que a pesquisa descritiva é muito usada na área da administração, isso por que ela busca conhecer e interpretar o assunto estudado sem interferir ou modificá-lo, sendo assim, a pesquisa busca identificar, descrever e classificar um fenômeno, deixando o mais claro possível para o leitor entender o objetivo abordado pelo autor. Tem uma semelhança com a pesquisa bibliográfica, onde em algumas vezes fica difícil de identificar em qual das duas a pesquisa é classificada. Diferente da pesquisa bibliográfica, que usa material já publicado, como livros e artigos em bibliotecas, a pesquisa documental busca em outros pontos, não só nos convencionais, sem precisar de um olhar analítico, as fontes de pesquisa se tornam mais dispersas, diversificadas. Tendo como exemplos de fontes as pesquisas em jornais, revistas, documentários, documentos oficiais, quadros, etc.

Fonseca (2002) corroborando com o assunto, bem como Gerhardt et al. (2009) falam que a pesquisa documental é feita em documentos recentes e antigos tendo sua autenticação científica confirmada, sendo bastante usada nas pesquisas de ciências sociais, buscando comparar características e tendências ligado a fatos sociais., porém a pesquisa documentada vem com um modelo bem estruturado fazendo com que os pesquisadores usem a imaginação e sua criatividade para levar a pesquisa a novos enfoques, dessa forma a pesquisa se mostra inovadora e trará para muitos temas contribuições importantes (GODOY, 1995). A pesquisa terá como instrumento de coleta de dados livros, artigos, jornais, documentos e documentários, ou seja, tudo que tenha relação com a problemática abordada, tentando, dá melhor forma, transmitir para o leitor o objetivo geral que foi proposto, tendo como forma de coleta de dados leitura e observação para transpassar os dados obtidos sobre a pesquisa, com uma análise bem completa dos dados obtidos e assim ter uma boa pesquisa, bem feita, que todos que venham a ler saibam que o objetivo proposto foi alcançado e bem exporto para todos. 


\section{RESULTADOS E DISCUSSÃO}

Com um aumento de 104 mil novos presos de 2014 para 2016, onde em 40\% são presos temporários e/ou àqueles que ainda esperam por suas sentenças, tendo um total de 726.712 a população prisional no Brasil, sendo que mais da metade da população carcerária tem idade entre 18 a 29 anos e 64\% são negros. Esses dados são do Levantamento Nacional de Informações Penitenciárias - Infopen, publicados no dia 8 de dezembro de 2017 pelo Depen - Departamento Penitenciário Nacional.

Tabela 1: Dados Infopen, 8 de dezembro 2017.

\begin{tabular}{|l|l|}
\hline BRASIL & 622.712 \\
\hline População prisional 2014 & 726.712 \\
\hline População prisional 2016 & 290.685 \\
\hline Presos temporários & 436.028 \\
\hline 18 a 29 anos & 465.096 \\
\hline Negros & \\
\hline
\end{tabular}

Diante de um montante de 1.436 presídios no país, onde se divide em administração pública e privada, não necessariamente na metade, mas com esses dois tipos de administração. Dentro da administração privada temos administração mista, essa que o governo e organização privada trabalham juntas, onde o estado fica responsável por alguma rebelião que venha acontecer no presídio, e nesse modelo temos 29 presídios, temos também administração com organizações sem fins lucrativos as ONGs, que entram também como administração privada, são 36 presídios, ou seja, com a administração privada são 65 presídios contra 1.371 de administração pública. Tendo o estado de Minas Gerais um foco maior por ter três presídios que trabalham com o sistema privado.

Tabela 2: Dados do Depen de 2017.

\begin{tabular}{|l|l|}
\hline PENITENCIÁRIAS & 1.371 \\
\hline ADM. Pública & 29 \\
\hline ADM. Mista & 36 \\
\hline ADM. Sem fins lucrativos & 65 \\
\hline ADM. Privada & 1.436 \\
\hline TOTAL & \\
\hline
\end{tabular}

Em foco temos o estado de Minas Gerais com o modelo de presídio público-privado - PPP. O estado tem três presídios que trabalham com esse padrão, porém o trabalho em questão manteve o foco em um, o de Ribeirão das Neves um dos primeiros a serem criados com o modelo de administração privada. Presídio inaugurado entre os anos de 2013 e 2014, tinha como plano a construção de cinco unidade prisionais, porém foram entregues nesse período apenas três, podendo comportar 2016 presos. Mesmo com o atraso e a falta de duas unidades, o modelo é tido como exemplo por muitos estados, com visitas constantes de governadores, diretores de organizações e curiosos para ver como é a administração e como funciona o presidio.

Com um sistema altamente sofisticado, o presídio de Ribeirão das Neves tem semelhança com os dos EUA, possuindo sistema eletrônico com portas automáticas, bloqueadores de celulares, câmeras de monitoramento. Em visita ao complexo, o fundador do Afroreggae, uma instituição não governamental, Sr. José Junior diz que por conhecer vários ambientes penais ele fica à vontade para debater sobre o assunto. 0 
mesmo relata que nunca viu nada igual em outras visitas a complexos. O presídio de Ribeirão das Neves tem uma infraestrutura organizada e tudo feito para seus devidos fins, passando para os presidiários a sensação de estarem em um ambiente adequado e mais humano. $O$ fato de tratarem os presidiários de forma educada, chamando-os pelo nome, mostra o modo diferente de agir que os a gentes daquela penitenciária usam.

Em conversa com os detentos, José Jr. também ouviu algumas reclamações que em termos não são tão convencionais, pois as reclamações vinham por parte da rígida rotina do presídio, o uso obrigatório do uniforme, a proibição de levar alimentos para celas e a eminente proibição de uso de celulares, a entrada de cigarros também é proibida, causando em muitos presidiários crise de abstinência, regras essas, usadas para controle e organização do complexo, tendo como obrigação, os detentos à cumprir.

Quanto ao trabalho dos detentos dentro da penitenciária, o presídio de Ribeirão das Neves não obriga os detentos trabalharem, mas o presídio têm parcerias para ofertarem oportunidades aos mesmos, sendo, que para o detento trabalhar, ele passa por avaliações feita pela Comissão Mista Multidisciplinar Técnica de Classificação, pois, ali tem vários perfis diferentes e penas diferentes, essa comissão é responsável por avaliar se o detento está apto a exercer uma função que não atrapalhe o dia a dia da penitenciária, àqueles detentos que cumprem a pena no sistema semiaberto tem por obrigação se apresentarem todo mês a folha de ponto ou qualquer documento que comprove a sua presença no trabalho, tendo como remuneração três quartos do salário mínimo, com carga horaria de 44 horas semanais, não tendo as regalias das leis trabalhistas sem ter nem um vínculo trabalhista com a pessoa que o contrata.

Visando uma economia para os cofres públicos o modelo de presídios privados é um ponto positivo para o estado, já que a empresa contratada tem total responsabilidade de admitir e pagar os agentes que atuam nos presídios. Odair Conceição, diretor da Associação Brasileira das Empresas Especializadas na Prestação de Serviços a Presídios - ABESP, relata que os agentes contratados têm a sua remuneração de acordo com o teto salarial do seu estado onde é bem menor que os dos agentes públicos, chegando a ganhar quatro vezes menos que eles, em virtude de um mau comportamento de um agente admitido por uma empresa terceirizada o modo de resolver é bem menos complicado, pois, por ser contratado em regime da CLT, seu desligamento é feito dentro de todos os direitos da lei, com o agente público o desligamento é complicado já que ele passou por um concurso e só poderá ser demitido por um procedimento formal disciplinar que na maioria das vezes demora anos para acontecer.

Mostrando-se ter uma organização melhor o sistema de administração privado tem pontos positivos e vem ganhando manchetes cada vez mais, por mais que não se tenham pesquisas sérias que falem dos índices de reincidências dos presos, estimasse que $70 \%$ dos presos do sistema privado não voltam, isso em comparação com o sistema público. Além de um ambiente mais agradável, projetos de ajuda para socializar o preso, o índice de reincidência mostra o quanto essa prática vem ganhando espaço. Dando mais ênfase, Gil Alessi e Odair Conceição, jornalistas do site de notícias El País Brasil, complementam dizendo que por não terem pesquisas concretas os índices de reincidências são constatados por ele, na sua empresa, com o sistema de contagem, lembrando que se o indivíduo for preso em outra instituição que não use o sistema de contagem de reincidente o dado é perdido. Com isso, o grupo reviver estima que o índice de reincidência é 
menor que $10 \%$, tendo como principal motivação a isso o alto número de presos que trabalham nas unidades chegando a $40 \%$, contra $12 \%$ do público, outro ponto também é ofertar estudo os detentos chegando a $70 \%$, contra $22 \%$ do sistema público.

\section{CONCLUSÕES}

Diante dos dados analisados constata-se que os objetivos da pesquisa foram alcançados, mostra para o público leitor diferenças relevantes na organização do sistema penitenciário público e privado, qual trabalha melhor com o ato da ressocialização do indivíduo ao meio social, o ambiente carcerário de ambas, qual delas tem um ambiente mais humano que proporciona para o presidiário o bem estar mais agradável na penitenciária, passando informações que o ajudem a identificar qual sistema é o melhor em relação os objetivos que a pesquisa propôs.

Relevância essa que mostra o quanto o sistema privado vem ganhando abertura no Brasil, com uma maneira de trabalho que ajuda os infratores dentro, e também, fora da prisão, já que os infratores dentro dos presídios privados tem uma atenção melhor voltada para educação e emprego causando assim uma ressocialização mas rápida para o indivíduo no âmbito social, informações essas, obtidas na análises dos dados.

Sem dúvida o sistema privado é melhor por se ter um número menor de reincidentes nos presídios, com projetos de pascerias com ONGS ajudando detentos a terem uma profissão e não precisarem mais estarem no mundo do crime, diminuindo esse índice de retorno do indivíduo para os presídios, com isso, a superlotação dos presídios iriam acabar, assim o surgimento de presídios com mais qualidades de vida no Brasil seriam mais constantes, falando em relação ao sistema pública que necessita muito de melhorias.

\section{REFERÊNCIAS}

ADORNO, S.; SALLA, F.. Criminalidade organizada nas prisões e os ataques do PCC. Estud. Av., São Paulo, v.21, n.61, pp.729, 2007.

CARAVANTES, G. R.; PANNO, C. C.; KLOECKNER, M. C.. Administração teoria e processo. São Paulo: Afiliada, 2008.

CERTO, S. C.. Administração moderna. 9 ed. São Paulo: Afiliada, 2013.

CHIES, L. A. B.. Privatização penitenciária e trabalho do preso. Pelotas: EDUCAT, 2000.

GERHARDT, T. E.; SILVERA, D. T.. Método de pesquisa. 1 ed. Porto Alegre: UFRGS, 2009.

GIL, A. C.. Métodos e técnicas de pesquisa social. São Paulo: Atlas, 1999.

GODOY, A. S.. Pesquisa qualitativa tipos fundamentais. Rev. Adm. Empres., São Paulo, v.35 n.3, 1995.

GOLDENBERG, M.. A arte de pesquisar. Rio de Janeiro: Record, 1997.
HAUSER, E. E.. A pena e o sistema penal: algumas considerações sobre sua legitimidade. Ijuí: Unijuí, 1997.

KWASNICKA, E. L.. Introdução à administração. 6 Ed. São Paulo: Atlas, 2009

LACOMBE, F. J. M.; HEILBORN, G. L. J.. Administração Princípios e Tendências. 3 ed. São Paulo: Saraiva, 2016.

MIRANDA, C.. Gestão penitenciária. 17 ed. São Paulo: RBA, 2017.

PINTO, S. R.. Aspectos da privatização de presídios: Origem, previsão legal, modelos, experiência brasileira e internacional. Revista Atena, n.1, p.101-119, 2019.

OSTERMANN, F. M.. A privatização de presídios como alternativa ao caos prisional. Res. Severa Verum Gaudium, Porto Alegre, v.2, n.1, 2010.

SÁ, A. A.. A 'ressocialização' de presos e a terceirização de presídios: impressões colhidas por um psicólogo em visita a dois presídios terceirizados. Revista da Fundação Escola Superior do Ministério Público do Distrito Federal e Territórios, Brasília, v.11, n.21, p.13-23, 2003. 
SALLA, F.; ALVAREZ, M. C.. Apontamentos para uma história das práticas da tortura no Brasil. Revista Brasileira de Ciências Criminais, n.63, p.277-308, 2006.

SALLA, F.. O PCC e a gestão dos presídios em São Paulo. Estudos CEBRAP, São Paulo, n.80, pp.21-41, 2008.
TAYLOR, F. W.. Princípios de administração cientifica. 7 ed. São Paulo: Atlas, 1995.

VERGARA, S. C.. Método de pesquisa em administração. São Paulo: Atlas, 2005

VIEIRA, V.. As tipologias, variações e características da pesquisa de marketing. Revista da FAE, Curitiba, v.5, n.1, p.61-70, 2002.

A CBPC - Companhia Brasileira de Produção Científica (CNPJ: 11.221.422/0001-03) detém os direitos materiais desta publicação. Os direitos referem-se à publicação do trabalho em qualquer parte do mundo, incluindo os direitos às renovações, expansões e disseminações da contribuição, bem como outros direitos subsidiários. Todos os trabalhos publicados eletronicamente poderão posteriormente ser publicados em coletâneas impressas sob coordenação da Sapientiae Publishing, da Companhia Brasileira de Produção Científica e seus parceiros autorizados. Os (as) autores (as) preservam os direitos autorais, mas não têm permissão para a publicação da contribuição em outro meio, impresso ou digital, em português ou em tradução. 